\title{
Acorn removal and dispersal by the dung beetle Thorectes lusitanicus: ecological implications
}

\author{
IGNACIO M. PÉREZ-RAMOS ${ }^{1}$, TEODORO MARAÑón ${ }^{1}$, \\ JORGE M. LOB O ${ }^{2}$ and JOSÉ R. VER D Ú ${ }^{3}{ }^{1}$ IRNASE, CSIC, PO Box 1052, Spain, ${ }^{2} \mathrm{MNCN}$, \\ CSIC, José Gutiérrez Abascal, 2, Spain, ${ }^{3} \mathrm{CIBIO}$, University of Alicante, Spain
}

\begin{abstract}
Plant-animal interactions, and in particular the processes of seed predation and dispersal, are crucial for tree regeneration and forest dynamics. A novel and striking case of interaction between a dung beetle (Thorectes lusitanicus) and two Quercus species ( $Q$. suber and $Q$. canariensis) in forests of southern Spain is presented here.

2. During the autumn, T. lusitanicus beetles (endemic to the southern Iberian Peninsula) bury and feed on single-seeded fruits (acorns) of Quercus, with important ecological implications.

3. Field experiments found differences in the removal rate of acorns by T. lusitanicus, depending on the type of microsite within the forest, the species of oak, the exclosure of large herbivores, and the forest site.

4. Acorn consumption by T. lusitanicus was studied under laboratory conditions, confirming for the first time that this dung beetle is a legitimate seed predator.

5. In addition, some buried acorns can be abandoned partially predated or even intact, and emerge as seedlings; thus, T. lusitanicus also has a potential role as secondary seed disperser.
\end{abstract}

Key words. Acorn predation, Mediterranean forest, Quercus canariensis, Quercus suber, secondary dispersal, Thorectes.

\section{Introduction}

Plant-animal interactions, and in particular the processes of seed predation and dispersal, have strong spatial and temporal variation, affecting the patterns of tree regeneration and forest dynamics. Seasonal production of fruits by tree species means a temporary abundance of resources, inducing a diet switch for many animals benefiting from these resources. For example, the direct benefit obtained by the birds feeding on fruits is accompanied by a benefit for the tree - dispersal of progeny - and represents a classic example of mutualism. The seasonal diet switch of birds (from insectivory to frugivory) has strong ecological implications for trees, determining the genetic and population structure of (bird-dispersed) tree populations (e.g. see Jordano \& Godoy, 2002).

In some cases, the tree-animal interaction can have a duality, varying from negative (seed predation) to positive (secondary dispersal). Such is the case of oaks and rodents. In Mediterranean oak savannas (dehesas), rodents (such as Apodemus sylvaticus)

Correspondence: Ignacio M. Pérez-Ramos. IRNASE, CSIC, PO Box 1052, 41080 Sevilla, Spain. E-mail: imperez@irnase.csic.es are the main predators of acorns, but at the same time, they bury them in protected microsites, such as among rocks, and these acorns are not always recovered and eaten. The newly emerged oak seedling enjoys a 'safe site' (sensu Harper, 1977) in these microsites, where it has a higher probability of survival from herbivory by large animals. The oak populations can ensure regeneration by a few seeds dispersed to safe sites, despite most of the seeds being eaten by the same rodents. In the absence of rodents, the seeds falling under the mother tree will emerge, but all the seedlings will be consumed by large herbivores, and regeneration will be impeded (Pulido \& Díaz, 2005). Thus, complex plant-animal interactions, including predation and dispersal, would determine the forest dynamics, these interactions being vital for the maintenance of ecosystem functions.

In tropical forests, dung beetles can have a role as secondary dispersers. They bury seed-containing faeces in the soil, favouring the establishment of seedlings (Estrada \& Coates-Estrada, 1991; Shepherd \& Chapman, 1998; Feer, 1999; Vulinec, 2000; Andresen, 2001; Vander Wall \& Longland, 2004). During that process of manipulation, seeds are safe, because, as the latter authors explicitly claimed, 'dung beetles do not consume seeds' (Vander Wall \& Longland, 2004). 
In a general study of oak regeneration, acorns of two species (Q. suber and $Q$. canariensis) were marked, dispersed, and monitored to follow the proportion of them predated by different animals (Pérez-Ramos et al., 2004). As a novel and unexpected observation, some of the acorns were removed and eaten by the dung beetle, T. lusitanicus. A monitoring study was then focused on the fate of that acorn-beetle interaction. In addition, beetles were fed with acorns of the same two species in laboratory experiments to demonstrate that they are able to eat intact seeds. Hence, this study documents for the first time the complex interaction between a dung beetle (Thorectes lusitanicus) and oaks ( $Q$. suber and $Q$. canariensis) in the Mediterranean forests of southern Spain, confirming that this dung beetle is a legitimate seed predator, and suggesting that the burying behaviour can favour the dispersion of acorns.

Using both field and laboratory experiments, we specifically aim: (i) to estimate the rate of removal of acorns by T. lusitanicus, comparing it with that by vertebrate species; (ii) to establish if the rate of acorn consumption by beetles significantly differs depending on the species of Quercus, the habitat structure, and the density of cattle present in each locality; (iii) and lastly, to discuss, after estimating the capacity of germination and emergence of buried (by beetles) acorns, the ecological implications of this beetle-oak interaction.

\section{Materials and methods}

\section{Study area}

The study area is located in the oak forests of the Aljibe Mountains, near the Strait of Gibraltar, in southern Spain. The dominant bedrock is Oligo-Miocenic sandstone, with a rough relief and a highest peak of $1094 \mathrm{~m}$ a.s.l. The climate is Mediterranean-type, with mild, wet winters, alternating with warm, dry summers. The mean temperature is $17^{\circ} \mathrm{C}$, and annual rainfall varies from 700 to $1200 \mathrm{~mm}$, depending on the effects of the orographic relief.

Vegetation is dominated by evergreen cork oak ( $Q$. suber) forests, mixed with deciduous oaks ( $Q$. canariensis), which are more abundant in the moister sites and valley bottoms. The shrubby understorey is diverse and rich in endemic taxa (see general vegetation description in Ojeda et al., 2000). Most of the forested area has been protected as the Natural Park of Los Alcornocales (meaning cork oak forests), covering about $1700 \mathrm{~km}^{2}$. Large herbivores, such as red deer (Cervus elaphus) and roe deer (Capreolus capreolus), are abundant in this forested park. In some places, domestic cows are allowed to graze freely in the forest.

Two forest sites within this study area were used for the field experiments: San Carlos del Tiradero (TIR) located at $36^{\circ} 9^{\prime} 46^{\prime \prime} \mathrm{N}$, $5^{\circ} 35^{\prime \prime} 39^{\prime \prime} \mathrm{W}$, and Panera (PAN) at $36^{\circ} 31^{\prime} 54^{\prime \prime} \mathrm{N}, 5^{\circ} 34^{\prime} 29^{\prime \prime} \mathrm{W}$, which are about $40 \mathrm{~km}$ apart. At each of these sites, one plot of about 1 ha has been fenced to exclude large herbivores, and monitored for tree regeneration since 1999 (Pérez-Ramos et al., 2004; Marañón et al., 2004; Pérez-Ramos \& Marañón, 2005). The two forest sites differed mainly in the presence of cattle, being very sporadic in TIR but regular in PAN, through all the seasons. The overstorey was dominated by $Q$. suber and $Q$. canariensis, and locally mixed with arborescent shrubs (Arbutus unedo and Phillyrea latifolia). The shrub understorey was dominated by Erica scoparia, E. arborea, Pistacia lentiscus, and Viburnum tinus.

\section{Studied organisms}

Thorectes lusitanicus Jeckel (Coleoptera, Scarabaeoidea, Geotrupidae) is a flightless, medium-sized species of dung beetle (with 130-175 mg specimen ${ }^{-1}$ of mean dry body weight), endemic to the southern Iberian Peninsula (Spain and Portugal) (LópezColón, 1995; Martín-Piera \& López-Colón, 2000). This species is classified as a 'telephagic tunneller', which has acquired the ability to ship dung from source to the nesting site, occasionally at several metres. The nests of T. lusitanicus can be buried 10-15 cm deep. The biology of this beetle species is poorly known, although it can be assumed to be similar to that of the close relative, T. laevigatus, of North Africa (Klemperer \& Lumaret, 1985).

The life cycle begins in the autumn (between September and November), when females lay their eggs in buried faeces of medium-sized herbivores, such as deer, sheep, goat, and rabbit, but also of cattle (Martín-Piera \& López-Colón, 2000). After immature development of 6-7 months, the adults emerge in spring. During the dry, warm summer they aestivate, while during the autumn they become active again and are very visible crawling over the forest floor (IPR, TM, \& JRV, pers. obs.).

Quercus suber L. (cork oak) is an evergreen tree dominating forests in a subhumid mediterranean-type climate, on acidic soils. Its distribution range covers the western half of the Mediterranean Basin (Italy, France, Spain, Portugal, Morocco, Algeria, and Tunisia). The fruit (acorn) is one of the largest in the Mediterranean forest (mean dry weight of $4.07 \mathrm{~g}$ and range of 1.56-7.90 g, $n=66$ ), and has a large seed with nutrientrich cotyledons protected by a hard pericarp (shell). The seed production is restricted to the autumn/early winter season (between October and February), and there is strong inter-year variability, due to a well-known masting behaviour; for example, estimates of acorn production (in dry weight) in the study site varied from $5 \mathrm{~g} \mathrm{~m}^{-2}$ (2003/04 cycle) to $33.15 \mathrm{~g} \mathrm{~m}^{-2}$ (2004/05 cycle) (Pérez-Ramos et al. unpublished).

Quercus canariensis Willd. is a semideciduous oak, locally abundant in the moister sites and usually mixed with $Q$. suber. The distribution range is restricted to the Iberian Peninsula (Spain and Portugal) and north-west Africa (Morocco and Algeria). Its acorns are somewhat smaller than those of $Q$. suber (mean dry weight of $1.56 \mathrm{~g}$ and range of $0.80-3.58 \mathrm{~g}, n=66$ ), and the seed dispersal is earlier (September-December). There is also a strong inter-year variability in seed production; for example, estimates in the study site varied between $28.5 \mathrm{~g} \mathrm{~m}^{-2}$ (2003/04 cycle) and $84.83 \mathrm{~g} \mathrm{~m}^{-2}$ (2004/05 cycle) (Pérez-Ramos, unpublished data). Information about the biology and ecology of this oak species is relatively scarce.

\section{Field experiments}

Seeds were collected under several trees of each oak species, during the period of peak production: October-November for 
Q. canariensis, and December-January for $Q$. suber. A sample of healthy, normal-sized acorns was made, using the floating method to discard those infected by moth or beetle larvae (Gribko \& Jones, 1995). The selected acorns were then stored on a moist vermiculite bed, in plastic trays, and kept at $2-4{ }^{\circ} \mathrm{C}$ until their use in the experiment.

Acorns were individually marked with a small spot and taken to the fenced forest plot, which only insects, rodents, and birds could gain access to. They were distributed in 48 dispersal units in three types of microsite: (i) open grassland; (ii) under trees without shrub understorey; and (iii) inside dense shrub and tree overstorey. In each dispersal unit, four acorns were placed on the ground, at the corners of a $0.5 \mathrm{~m}$ square, making a total of 192 seeds for each oak species, each time. To mark the dispersal units, a small flag was placed $0.5 \mathrm{~m}$ from each border, to avoid an attraction effect. The minimum separation between different units was $10 \mathrm{~m}$, approximately.

All acorns were monitored periodically, noting the number of them predated in situ, the number removed, and, when possible, the identity of the predators (based on several types of evidence). The acorns predated by rodents or birds were identified by signs of gnawing or pecking respectively. When the experimental acorn had been removed, it was sought (digging within a circle of $50 \mathrm{~cm}$ in radius) to verify evidence of manipulation by the dung beetle, T. lusitanicus. In many cases, the acorn was found with the beetle inside, and in other cases the buried acorn was found with a circular hole (beetle-sized) and was partially or completely emptied. When a buried acorn was found intact, it was considered to have been manipulated by beetles only if a beetle was also buried with it.

All the experimentally dispersed acorns were periodically checked during 3-4 months, until there was no evidence of beetle activity. In early spring, a last seed census was made; buried acorns were sought and excavated, and the proportion of consumed seed mass was estimated. The acorns manipulated by beetles were sorted into two categories: (i) nonviable acorns (with damaged embryo, usually showing losses of seed biomass up to $50 \%$ ), and (ii) viable acorns (buried by beetles but intact or only partially consumed, usually with losses below 50\% and undamaged embryo). During this last census, the number of established seedlings from buried acorns was also recorded. The experimental dispersal and subsequent monitoring was repeated during two cycles: 2003-04 and 2004-05.

The respective experiments for the two oak species were started at different times, depending on the temporal displacement in the peak of seed production and natural dispersal. The 192 acorns of $Q$. canariensis were first dispersed in mid October (2003) or early November (2004), while $Q$. suber acorns were taken to the field and set up in early December (2003 and 2004), in different - though neighbouring - dispersal units so there was no interference between the results for the two species. In a second, parallel experiment, to investigate the possible interference from the impact of large animals such as deer and cattle (especially cows) in the removal by $T$. lusitanicus, we dispersed acorns outside the fenced plot to estimate the total rate of postdispersal predation. A similar design, but with 24 dispersal units (of four acorns) for each species, was used. Acorns were distributed among the three types of microsite, in the vicinity of the fenced plot but outside the enclosure, at the same dispersal time: $Q$. canariensis in early autumn, and $Q$. suber in late autumn, in 2003 and 2004. The whole set of dispersal experiments and monitoring was replicated in the two forest sites studied (TIR and PAN), making a grand total of 2304 acorns of two oak species monitored, during 2 years, for evidence of manipulation and burial by dung beetles.

\section{Laboratory experiments}

To verify that Thorectes lusitanicus is a legitimate seed predator, and not a scavenger using acorns partially eaten by other animals, such as rodents, a laboratory experiment was carried out. First, several beetles were manually collected from the same forest sites used for the dispersal experiments. They were transported to the laboratory and distributed among feeding units. Each unit had four beetles inside a plastic box of $25 \times 15$ $\mathrm{cm}$ and $15 \mathrm{~cm}$ in height, with a thin layer of forest soil from the same field site. The boxes were kept moist inside by spraying with water periodically. Four acorns were provided in each box to feed the beetles.

To test the seed-predating ability of the beetles, three types of acorn were provided: (i) intact acorns, with the shell closed; (ii) germinating acorns, with the shell splitting where the new root was protruding; and (iii) cut acorns, with the cotyledons fully exposed. Fifteen units (four acorns per unit) were distributed among the three treatments (acorn types), and for each oak species: a total of 120 beetles and 60 acorns of each species. The acorns were monitored every 2-3 days, for about 30 days. Each time, the number of acorns with evidence of being predated was counted, and the proportion of consumed seed mass (consumption rate) was estimated. When the experiment finished, the beetles were returned to the forest.

\section{Statistical analysis}

The rate of removal of acorns by $T$. lusitanicus in field experiments was treated as a multinomial ordinal dependent variable, with four categories depending on the number of acorns manipulated by beetles in each dispersal unit of four acorns $(0,1,2$, and more than 2$)$. The relationships between this variable and four explanatory variables were established by using Generalized Linear Models (GLZ; McCullagh \& Nelder, 1989). The explanatory variables used were the three microsite categories, the two oak species, the two locations (exclosure or not), and the two forest sites (TIR and PAN). GLZs are an extension of linear models that allow nonlinearity in the data, as well as a wide range of model specification distributions other than the normal distribution of the random component. An ordinal multinomial error distribution was used, assuming a logit relationship between the dependent and explanatory variables (the link function).

The same type of analysis was carried out to study the differences between the two oak species in the proportion of 'positive burials' - that is, when acorns buried and manipulated by beetles did get to establish as seedlings. In this case, the 
variable was treated as a binomial $(1=$ recorded seedling; $0=$ no evidence of emergence), assuming a logit relationship between this variable and the explanatory variable (oak species).

The acorn consumption rate, in the laboratory experiments, was measured as the number of days needed to consume at least half of the seed mass (T50). This variable was transformed in a normal distribution using its square root. Differences between treatments and species were determined using a factorial ANOVA.

All analyses were carried out using STATISTICA version 6.0 (StatSoft Inc. 2001).

\section{Results}

\section{Removal rate under field conditions}

The total rate of removal by different predators of the experimentally dispersed acorns was very high, reaching percentages close to $100 \%$ in certain microsites (Table 1 ). About $88 \%$ of total placed acorns were removed by small vertebrates, especially rodents, while about $6 \%$ of them were removed by beetles. In certain microsites located under trees and situated outside the exclosure, however, a significant proportion of the acorns were manipulated by beetles: up to $40 \%$ for $Q$. canariensis and $25 \%$ for $Q$. suber (Table 1).

The rate of removal by beetles differed significantly between microsites, exclosure locations, oak species, and localities (Table 2 and Fig. 1). Locality was the most influential factor (Fig. 1a); thus, at site PAN, where the density of large grazers was higher, there was a higher proportion (20-40\%) of acorns manipulated by beetles, while at site TIR, where the deer population was smaller and cattle were absent, only a negligible proportion of acorns were predated by beetles.

The proportion of removal due to T. lusitanicus was significantly higher for $Q$. canariensis acorns (Table 2; Fig. 1b). It was higher in the 'under-tree, without-shrubs' microsite type, just where the rate of removal by rodents was generally lower (Table 2; Fig. 1c). Lastly, the number of acorns removed by beetles was higher outside the exclosure, where large animals grazed and defecated, probably attracting beetles (Table 2; Fig. 1d).

Table 1. Results of the censuses of acorns manipulated by beetles or by other predators, distinguishing oak species (Quercus canariensis and Q. suber), type of microsite (open grassland, dense shrub and under tree without shrub) and exclusion of large herbivores (inside and outside the fence). Acorns manipulated by the beetle T. lusitanicus have been sorted in two consumption categories. Established seedlings from buried acorns were also counted during the last census and they are indicated. Data refer to one of the forest sites (Panera) during the 2004-05 cycle. Total of dispersed acorns, for each Quercus species and in each microsite type, were 64 inside the fence and 32 outside.

\begin{tabular}{|c|c|c|c|c|c|c|}
\hline & \multicolumn{6}{|c|}{ Microsite type } \\
\hline & \multicolumn{2}{|c|}{ Open grassland } & \multicolumn{2}{|c|}{ Under tree } & \multicolumn{2}{|c|}{ Dense shrub } \\
\hline & Acorns & Seedlings & Acorns & Seedlings & Acorns & Seedlings \\
\hline \multicolumn{7}{|l|}{ Quercus canariensis } \\
\hline \multicolumn{7}{|l|}{ i) Inside the exclosure } \\
\hline ii) Non-removed & 1 & 0 & 6 & 5 & 0 & 0 \\
\hline \multicolumn{7}{|l|}{ ii) Manipulated by beetles } \\
\hline iii) Non-viable & 0 & 0 & 5 & 0 & 1 & 0 \\
\hline iii) Viable & 0 & 0 & 0 & 0 & 0 & 0 \\
\hline ii) By other predators & 63 & 1 & 53 & 1 & 63 & 2 \\
\hline \multicolumn{7}{|l|}{ i) Outside the exclosure } \\
\hline ii) Non-removed & 8 & 5 & 2 & 1 & 3 & 2 \\
\hline \multicolumn{7}{|l|}{ ii) Manipulated by beetles } \\
\hline iii) Non-viable & 2 & 0 & 9 & 0 & 0 & 0 \\
\hline iii) Viable & 1 & 1 & 4 & 2 & 0 & 0 \\
\hline ii) By other predators & 21 & 1 & 17 & 0 & 29 & 0 \\
\hline \multicolumn{7}{|l|}{ Ouercus suber } \\
\hline \multicolumn{7}{|l|}{ i) Inside the exclosure } \\
\hline ii) Non-removed & 0 & 0 & 4 & 3 & 0 & 0 \\
\hline \multicolumn{7}{|l|}{ ii) Manipulated by beetles } \\
\hline iii) Non-viable & 0 & 0 & 0 & 0 & 1 & 0 \\
\hline iii) Viable & 0 & 0 & 1 & 1 & 0 & 0 \\
\hline ii) By other predators & 64 & 0 & 59 & 0 & 63 & 0 \\
\hline \multicolumn{7}{|l|}{ i) Outside the exclosure } \\
\hline ii) Non-removed & 0 & 0 & 12 & 10 & 1 & 0 \\
\hline \multicolumn{7}{|l|}{ ii) Manipulated by beetles } \\
\hline iii) Non-viable & 1 & 0 & 2 & 0 & 0 & 0 \\
\hline iii) Viable & 0 & 0 & 6 & 5 & 0 & 0 \\
\hline ii) By other predators & 31 & 0 & 12 & 0 & 0 & 0 \\
\hline
\end{tabular}


Table 2. Results of the regression analysis using Generalized Linear Models between the number of acorns manipulated by $T$. lusitanicus, and four explanatory variables: microsite, oak species, exclosure, and locality. Acorn removal rate is a multinomial ordinal dependent variable with four categories: $0,1,2$, and $>2$ acorns removed by beetles by dispersal unit. Microsite categories are three: (i) open grassland; (ii) under trees without shrub understorey; and (iii) inside dense shrub and tree overstorey. Oak species are Quercus canariensis and Q. suber. Exclosure refers to the location of acorns inside (exclosure) or outside a fenced plot. The two localities were San Carlos del Tiradero (TIR) and Panera (PAN).

\begin{tabular}{|c|c|c|c|c|c|c|}
\hline & Deviance & $\begin{array}{l}\text { Change in } \\
\text { deviance }\end{array}$ & $\begin{array}{l}\text { Explained } \\
\text { deviance (\%) }\end{array}$ & $x^{2}$ & d.f. & $P$ \\
\hline Null model & 426.76 & & & & & \\
\hline Microsite & 401.56 & 25.19 & 5.90 & 28.68 & 6 & $<0.0001$ \\
\hline Oak species & 414.34 & 12.41 & 2.91 & 13.04 & 3 & 0.005 \\
\hline Exclosure & 422.39 & 4.36 & 1.02 & 10.44 & 3 & 0.02 \\
\hline Locality & 383.78 & 42.98 & 10.07 & 46.15 & 3 & $<0.0001$ \\
\hline
\end{tabular}

\section{Acorn burial and seedling establishment}

The damage caused by T. lusitanicus to acorns of the two oak species was very different. We estimated that $54.5 \%$ of the $Q$. canariensis acorns removed and buried were completely consumed by beetles (nonviable acorns), while the rest were buried but not eaten, or only partially consumed (viable acorns). In contrast, only $36.4 \%$ of the removed $Q$. suber acorns were completely eaten, while $63.6 \%$ of them were buried but remained almost intact during the complete sampling period (Table 1).

The proportion of consumed acorn biomass affects the ability to germinate and emerge as a seedling. Only the buried acorns that kept the embryo intact (not consumed or partially eaten) were able to recruit new oak seedlings (Table 1 ). Thus, $54.5 \%$ of the total $Q$. suber acorns buried by beetles established as seedlings, whereas only $13.6 \%$ did so for $Q$. canariensis (Wald statistics $=5.46$; d.f. $=1 ; P=0.019)$.

When the two oak species were compared, despite $Q$. canariensis showing a higher rate of removal by beetles, the positive burial effect was higher for $Q$. suber. We can predict that one out of 100 dispersed acorns of $Q$. canariensis, and two out of 100 for $Q$. suber, are buried by beetles and do establish as seedlings. Thus, the dung beetle T. lusitanicus seems to be an important secondary disperser of seeds of the two oak species.

\section{Acorn predation by beetles under laboratory conditions}

The main result under laboratory conditions is that $T$. lusitanicus is able to gnaw the hard coat of acorns and to feed on the cotyledons, completely consuming the seed in a few weeks. Thus, it is confirmed that $T$. lusitanicus is a legitimate oak seed predator.

As expected, the rate of consumption of partially exposed seeds (germinated or cut) was higher than for intact acorns $(F=6.0$; d.f. $=2 ; P=0.004$ ) (Fig. 2). The protective effect of the shell of $Q$. suber acorns, measured as the number of days needed to consume at least half of the seed mass (T50), was strong; there was almost no effect, however, for $Q$. canariensis acorns, which were more rapidly consumed than Quercus suber acorns $(F=8.08$; d.f. $=1 ; P=0.006$ ), even with intact pericarp (Fig. 2).

\section{Discussion}

Thorectes lusitanicus as seed predator

This study documents for the first time how a dung beetle, T. lusitanicus, living in a forest environment with seasonal abundance of seed (acorn) resources on the ground, feeds abundantly on acorns. Is that a seasonal diet shift from coprophagy to balanophagy? The question needs to be answered with further studies.

The behaviour of the dung beetle in burying the acorn and eating it has been documented in the field. When the beetle finds an acorn, it buries it a few centimetres into the soil, and begins to eat it (gnawing at one of the poles). After a few weeks, the acorn is completely eaten and the beetle stays, probably hibernating, inside the empty pericarp. In many cases, however, the beetle buries the acorn and leaves it intact or eats only a small part of it; the seed is then able to germinate and establish as a seedling. The ability of the beetle to open intact acorns and consume them has also been documented, under laboratory conditions. These findings contradict the accepted assumption that 'dung beetles do not consume seeds' (Vander Wall \& Longland, 2004), and confirm the exception of Thorectes lusitanicus as a post-dispersal oak seed predator.

The ability to consume acorns must involve morphological and digestive adaptations in this dung beetle. Many derived characters related to good exploitation of dry dung have been observed in the mouthparts of Thorectes genus, including T. lusitanicus. These hard-diet consumers have mandibles with strongly developed denticles and well-developed molar areas to triturate dry pellets (Verdú \& Galante, 2004). Such morphological adaptations seem sufficient for gnawing the hard coat of acorns and consuming the seed completely. Despite previous studies (Palestrini \& Zunino, 1985) showing that Thorectes beetles can feed on a variety of resources (such as faeces and rotten fruits), no evidence was previously known regarding acorn eating. In addition to being physically capable of ingesting the food, T. lusitanicus must also have a digestive system able to process the tannin-rich oak seeds; preliminary results suggest the existence of a diverse microbial flora that would allow the wide trophic niche of this species. More research is needed on the evolutionary changes in the anatomy, physiology, foraging behaviour, and life cycle of this intriguing dung beetle. 

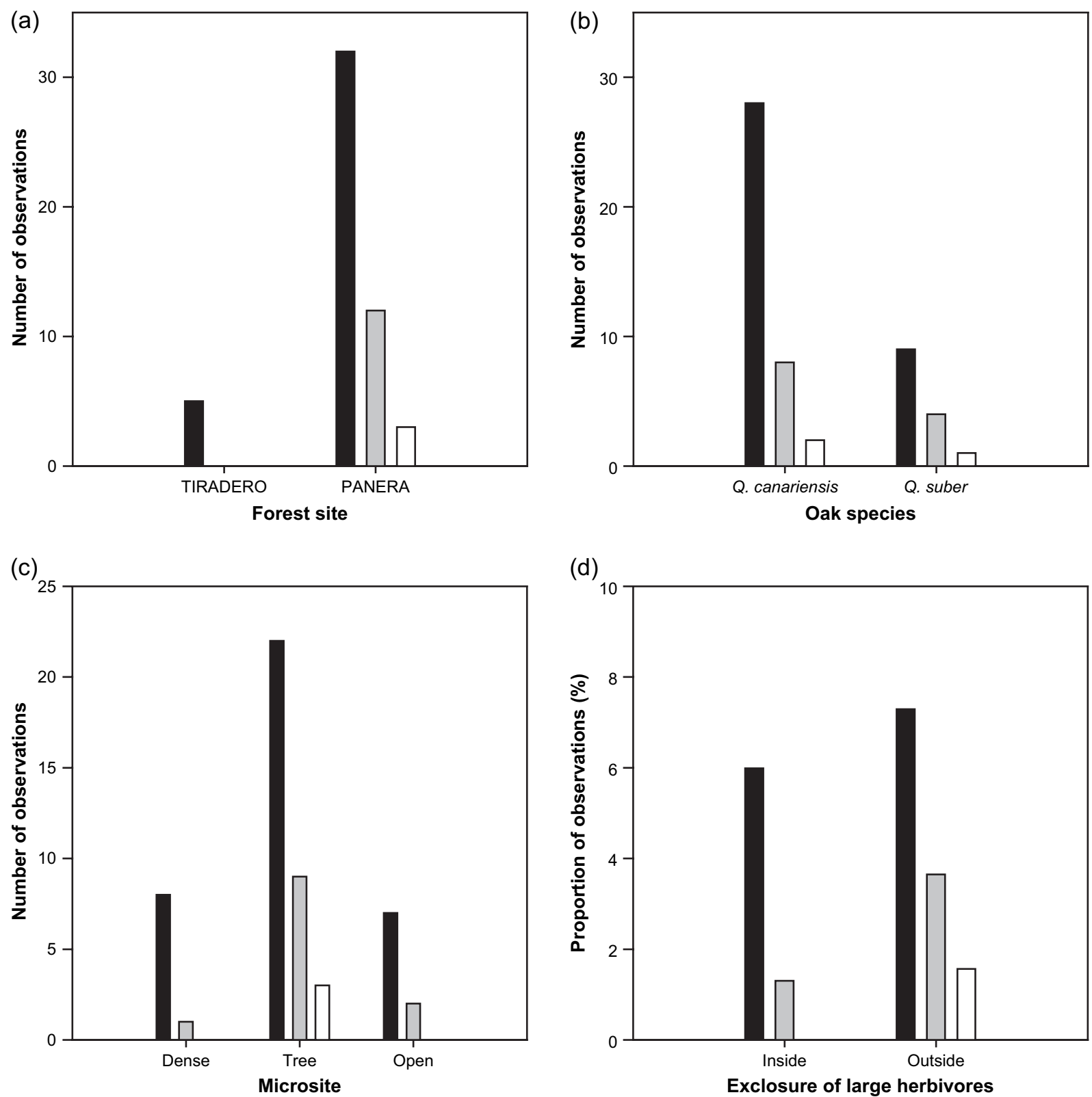

Fig. 1. Number of observations (dispersal units) pertaining to three acorn removal categories, according to the number of manipulated acorns (out of four): one ( $25 \%$, black bar), two (50\%, grey bar) and more than two ( $>50 \%$, white bar) (when there were not evidences of removal - category $0-$ they were not represented), plotted against (A) the two forest localities: San Carlos del Tiradero, and Panera; (B) the two oak species: Quercus canariensis, and Q. suber; (C) the three microsite types: open grassland (Open), under trees without shrub understorey (Tree), and inside dense shrub and tree overstorey (Dense); and (D) the two locations with large grazers: inside of the fenced plot (Inside), and outside (Outside) (in this case, with unequal number of dispersal units in fenced and unfenced plots, the proportion instead of actual number was used).

From the oaks' perspective, the proportion of seed crop loss due to T. lusitanicus (1-40\%) was relatively small compared with that due to other predators, mainly rodents.

The pattern of post-dispersal seed predation by $T$. lusitanicus varied spatially. The highest values were found in the unfenced zone, where large herbivores grazed and defecated. Dung is probably the main all-year source of food for these beetles, and is needed for nesting and to feed the larvae (Hanski \& Cambefort, 1991); thus, a spatial dependence on dung availability is expected. In general, dung beetle assemblages are able to readjust their populations rapidly to the level of available trophic resources (Lumaret et al., 1992; Kadiri et al., 1997), reacting both to changes in the type of ruminant and to the history of cattle activity (Lumaret et al., 1992; Lobo et al., 1998, 2006). Oak forests harbouring higher numbers of deer and/or cattle will support more dung beetles, and in consequence a higher proportion of acorns will be buried and eaten (totally or partially) by them. The dependence on the dung availability was 


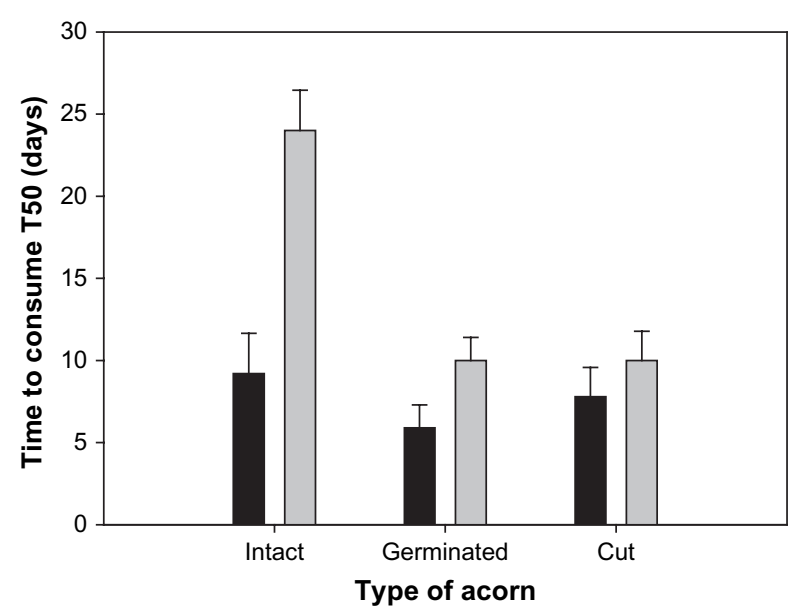

Fig. 2. Rate of acorn consumption (mean and SE bars) by Thorectes lusitanicus under laboratory conditions, for three modes of offering the acorns (intact, germinated or cut), and for the two oak species: Quercus suber (grey bar) and Q. canariensis (black bar). Values of $T_{50}$ represent the time (days) needed by the beetles to consume about half of the seed mass.

corroborated by the differences in proportion of beetlemanipulated acorns between localities with a different density of large herbivores.

The forest spatial heterogeneity is another source of variability able to explain the differences in the rate of beetle seed predation. T. lusitanicus has been observed crawling through the mosaic of microsites in the forest. When acorns were dispersed equally (in the experiment) among different types of microsite, however, the highest proportion of manipulation by beetles was found under trees without shrub understorey. This type of microsite with a higher availability of acorns (dispersed by gravity) probably attracts a higher number of beetles, although this pattern should be confirmed by a study of their foraging behaviour. In contrast, under dense shrub and tree layers, the acorn fall can be high, but competition from rodents, which tend to forage in these types of habitat, is also higher (Herrera, 1995; Pulido \& Díaz, 2005).

There was a significant difference between oak species with regard to the rate of seed manipulation by beetles, which can be partly related to the differential timing in acorn fall, and thus in availability. When $Q$. canariensis acorns fall, in early autumn, and first become available to beetles, temperatures are not too low, and beetle populations increase their density and activity. Later, when $Q$. suber acorns fall, in late autumn/early winter, many beetles are already buried with a $Q$. canariensis acorn, temperatures are lower, and beetle activity is reduced. Furthermore, there was also a significant difference between oak species with regard to the rate of seed consumption, which has profound demographic implications. Once buried, the probability of being completely consumed was much higher for $Q$. canariensis than for $Q$. suber. The consequence for oak regeneration is that, despite the higher manipulation rate found in the experimentally dispersed acorns of $Q$. canariensis, the proportion of buried, surviving embryos was almost half that for $Q$. suber.

Under laboratory conditions, intact $Q$. canariensis acorns are consumed more rapidly by beetles than are those of $Q$. suber, probably because they have a weaker shell. The differential rates of removal and consumption between oak species are thus explained by the timing of acorn fall, and the hardness of the shell. These patterns do not necessarily mean an active preference of beetles for acorns of one particular oak species - more studies are needed for confirmation.

Thorectes lusitanicus as seed disperser

The innate behaviour of many dung beetles in burying portions of dung in the soil has been related to the competition for resources, also allowing protection from adverse climatic conditions, and reducing the risk of being predated (Hanski \& Cambefort, 1991). In tropical forests, dung beetles are secondary dispersers of small seeds inside the faeces, which are buried and thus protected from seed predators (e.g. see Andresen, 2003; Vander Wall \& Longland, 2004).

In the singular case of $T$. lusitanicus, the beetles follow that burying behaviour, pulling back pieces of dung with their front legs to a suitable resting or nesting place (Verdú \& Galante, 2004). This behaviour is also followed when they manipulate singleseeded, ball-like fruits (acorns), although in this case the seed is buried by the beetle actively, rather than passively within the dung. The positive consequence for oak regeneration is that a few of these buried seeds are not completely consumed, most of them keeping the ability to emerge and establish as seedlings, while protected from other seed predators. Those seedlings will also have deeper roots and a higher probability of surviving the summer drought. A similar case of the dual role of seed predator vs. disperser has been studied for birds (Gómez, 2003) and rodents (Pulido \& Díaz, 2005), and it is accepted that the small proportion of buried seeds surviving in safe sites after being discarded or forgotten by predators is crucial for the tree population dynamics.

The complex interactions in these forests of the acorn-eating dung beetle with other dung beetles competing for faeces, as well as with rodents competing for acorns, with the predators of dung beetles (birds and mammals), and with the large herbivores providing their food (faeces), are virtually unknown. Moreover, the highly variable inter-year acorn crop, characteristic of oak species, will affect the beetle population dynamics and the fate of these complex interactions. Understanding and preserving that 'interaction biodiversity' (sensu Thompson, 2002) must be considered essential for the conservation of Mediterranean forests.

\section{Acknowledgements}

We thank the Consejería de Medio Ambiente (Andalusian Government), and the Director of Los Alcornocales Natural Park, Felipe Oliveros, for the facilities and support to carry out our field-work. We also thank Pedro Jordano for his advice in the experimental design and Maite Domínguez for field assistance. This study was supported by grant PFPU-MEC to IMPR, and by the Spanish MEC projects Heteromed (REN2002-4041-C0202) and Dinamed (CGL2005-5830-C03-01). This research is part of the Redbome and Globimed networks in forest ecology. 


\section{References}

Andresen, E. (2001) Effects of dung presence, dung amount and secondary dispersal by dung beetles on the fate of Micropholis guyanensis (Sapotaceae) seeds in Central Amazonia. Journal of Tropical Ecology, 17, 61-78.

Andresen, E. (2003) Effect of forest fragmentation on dung beetle communities and functional consequences for plant regeneration. Ecography, 26, 87-97.

Estrada, A. \& Coates-Estrada, R. (1991) Howler monkeys (Alouatta palliata), dung beetle (Scarabaeidae) and seed dispersal: ecological interactions in the tropical rain forest of Los Tuxtlas, Mexico. Journal of Tropical Ecology, 7, 459-474.

Feer, F. (1999) Effects of dung beetles (Scarabaeidae) on seeds dispersed by howler monkeys (Alouatta seniculus) in the French Guianan rain forest. Journal of Tropical Ecology, 15, 129-142.

Gómez, J.M. (2003) Spatial patterns in long-distance dispersal of Quercus ilex acorns by jays in an heterogeneous landscape. Ecography, 26, 573-584.

Gribko, L.S. \& Jones, W.E. (1995) Test of float method of assessing northern red oak acorn condition. Tree Planter's Notes, 46, $143-147$.

Hanski, I. \& Cambefort, Y. (1991) Dung Beetle Ecology. Princeton University Press, Princeton, NJ.

Harper, J.L. (1977) Population Biology of Plants. Academic Press, London, U.K.

Herrera, J. (1995) Acorn predation and seedling production in a lowdensity population of cork oak (Quercus suber L.). Forest Ecology and Management, 76, 197-201.

Jordano, P. \& Godoy, J.A. (2002) Frugivore-generated seed shadows: a landscape view of demographic and genetic effects. Seed Dispersal and Frugivory: Ecology, Evolution and Conservation (ed. by D. J. Levey, W. R. Silva and M. Galetti), pp. 305-321. CAB International, Wallingford, U.K.

Kadiri, N., Lobo, J.M. \& Lumaret, J.P. (1997) Conséquences de l'interaction entre préferences pour l'habitat et quantité de ressources trophiques sur les communautés d'insectes coprophages (Coleoptera, Scarabaeidae). Acta Oecologica, 17, 107-119.

Klemperer, H.G. \& Lumaret, J.P. (1985) Life-cycle and behavior of the flightless beetles Thorectes-sericeus Jekel, Thorectes-albarracinus Wagner, and Thorectes-laevigatus-cobosi Baraud (ColGeotrupidae). Annales de la Société Entomologique de France, 21, 425-431.

Lobo, J.M., Lumaret, J.P. \& Jay-Robert, P. (1998) Sampling dungbeetles in the French Mediterranean area: effects of abiotic factors and farm practices. Pedobiologie, 42, 252-266.

Lobo, J.M., Hortal, J. \& Cabrero-Sañudo, F. (2006) Regional and local influence of grazing activity on the diversity of a semi-arid dung beetle community. Diversity and Distributions, 12, 111-123.
López-Colón, J.I. (1995) El género Thorectes Mulsant, 1842 (Coleoptera Scarabaeoidea, Geotrupidae) en la fauna europea. Giornale Italiano Di Entomologia, 7, 355-388.

Lumaret, J.P., Kadiri, N. \& Bertrand, M. (1992) Changes in resources: consequences from the dynamics of dung beetle communities. Journal of Applied Ecology, 29, 349-356.

Marañón, T., Zamora, R., Villar, R., Zavala, M.A., Quero, J.L., PérezRamos, I., Mendoza, I. \& Castro, J. (2004) Regeneration of tree species and restoration under contrasted Mediterranean habitats: field and glasshouse experiments. International Journal of Ecological and Environmental Sciences, 30, 187-196.

Martín-Piera, F. \& López-Colón, J.I. (2000) Coleoptera, Scarabaeoidea I. Fauna Ibérica, 14 (ed. by M. A. Ramos and J. L. Nieves-Aldrey) Museo Nacional de Ciencias Naturales, CSIC, Madrid.

McCullagh, P. \& Nelder, J.A. (1989) Generalized Linear Models. Chapman \& Hall, London.

Ojeda, F., Marañón, T. \& Arroyo, J. (2000) Plant diversity patterns in the Aljibe Mountains (S. Spain): a comprehensive account. Biodiversity and Conservation, 9, 1323-1343.

Palestrini, C. \& Zunino, M. (1985) Osservazioni sul regime alimentare dell'adulto di alcune specie del genere Thorectes Muls. Bolletino Del Museo Regionale Di Scienze Naturali Di Torino, 3, 183-190.

Pérez-Ramos, I.M. \& Marañón, T. (2005) Limitaciones en la regeneración natural de las especies leñosas de un bosque mediterráneo. Almoraima, 31, 129-135.

Pérez-Ramos, I.M., Domínguez, M.T. \& Marañón, T. (2004) Depredación de semillas de alcornoque (Quercus suber) y quejigo $(Q$. canariensis): una aproximación experimental. Revista de la Sociedad Gaditana de Historia Natural, 4, 175-180.

Pulido, F.J. \& Díaz, M. (2005) Regeneration of a Mediterranean oak: a whole-cycle approach. Écoscience, 12, 92-102.

Shepherd, V.E. \& Chapman, C.A. (1998) Dung beetles as secondary seed disperser: impact on seed predation and germination. Journal of Tropical Ecology, 14, 199-215.

Thompson, J.N. (2002) Plant-animal interactions: future directions. Plant-Animal Interactions. An Evolutionary Approach (ed. by C. M. Herrera and O. Pellmyr), pp. 236-247. Blackwell, Oxford.

Vander Wall, S.B. \& Longland, W.S. (2004) Diplochory: are two seed dispersers better than one? Trends in Ecology and Evolution, 19, $155-161$.

Verdú, J.R. \& Galante, E. (2004) Behavioural and morphological adaptations for a low-quality resource in semi-arid environments: dung beetles (Coleoptera, Scarabaeoidea) associated with the European rabbit (Oryctolagus cuniculus L.). Journal of Natural History, 38, 705-715.

Vulinec, K. (2000) Dung beetles (Coleoptera: Scarabaeidae), monkeys, and conservation in Amazonia. Florida Entomologist, 83, 229-241.

Accepted 4 October 2006 